\title{
Comparison of the Effects of Middle Ear Implants and Conventional Hearing Aids on Cognitive Function
}

\author{
Choon Dong Kim ${ }^{1}$, Hyun Sang Cho ${ }^{1}$, Young Soon Yang ${ }^{2}$, Hun Hee Baek ${ }^{1}$, Sung Hwan Lim ${ }^{1}$, \\ Hye Mi Park ${ }^{1}$, Ga Eul Choi ${ }^{1}$, Eun Joo Choi ${ }^{3}$, and Shin Ae Kim ${ }^{4}$ \\ ${ }^{I}$ Departments of Otorhinolaryngology-Head and Neck Surgery, ${ }^{2}$ Neurology, Veterans Health Service Medical Center, Seoul; and \\ ${ }^{3}$ Department of Speech-Language Pathology, Gachon University Graduate School of Professional Therapy, Seongnam; and \\ ${ }^{4}$ Department of Internal Medicine, Seoul National University Hospital, Seoul, Korea
}

\author{
인공중이와 보청기가 인지기능 향상에 미치는 영향의 비교 \\ 김춘동 ${ }^{1} \cdot$ 조현상 ${ }^{1}$ 양영순 ${ }^{2} \cdot$ 백훈희 $^{1} \cdot$ 임성환 $^{1} \cdot$ 박혜미 $^{1} \cdot$ 최가을 $^{1} \cdot$ 최은주 $^{3} \cdot$ 김신애 ${ }^{4}$ \\ 중앙보훈병원 이비인후과, ${ }^{1}$ 신경과, ${ }^{2}$ 가천대학교 특수치료대학원 언어치료학과, ${ }^{3}$ 서울대병원 내과 ${ }^{4}$
}

\author{
Received June 27, 2017 \\ Revised September 20, 2017 \\ Accepted September 29, 2017 \\ Address for correspondence \\ Choon Dong Kim, MD \\ Department of Otorhinolaryngology- \\ Head and Neck Surgery, Veterans \\ Health Service Medical Center, \\ 53 Jinhwangdo-ro 61-gil, \\ Gangdong-gu, Seoul 05368, Korea \\ Tel $+82-2-2225-1384$ \\ Fax $+82-2-2225-1385$ \\ E-mail cdkim2@hanmail.net
}

Background and Objectives The association between hearing impairment and cognitive function has been established in previous studies. The aim of this study was to compare the effects of conventional hearing aids and middle ear implants on cognitive function.

Subjects and Method This study included 22 participants who underwent middle ear implantation between October 2013 and September 2016. Their mean age at surgery was 70 years. Using Pure tone audiometry (PTA), the Speech discrimination test (SDT), and the Abbreviated Profile of Hearing Aid Benefit (APHAB) questionnaire, we compared audiologic benefits of three conditions [without hearing aids, with conventional hearing aids, or with Vibrant Sound bridge (VSB)]. Cognitive ability was evaluated using neuropsychological testings (Seoul Neuropsychological Screening Battery) at intervals of approximately eight weeks.

Results The results of PTA showed a $7.96 \mathrm{~dB}$ HL gain with conventional hearing aids and a $10.00 \mathrm{~dB}$ HL gain with the use of VSB. SDT results showed a $4.10 \%$ gain with conventional hearing aids and a $10 \%$ gain with the use of VSB. Results of the APHAB questionnaire showed a significant increase with the use of VSB compared to conventional hearing aids. In the Korean Mini-Mental State Examination, a slight improvement was observed after middle ear implantation. In the Digit Span Test and Korean-Boston Naming Test, a significant improvement was seen with the use of VSB compared to conventional hearing aids.

Conclusion The use of middle ear implants in rehabilitation of hearing communication in patients showed improvements in cognitive abilities, compared to the use of conventional hearing aids. Korean J Otorhinolaryngol-Head Neck Surg 2017;60(12):633-9
서 론

World Health Organization의 2015년 조사에 따르면 전 세 계적으로 약 3억 6천만 명이 난청장애를 겪고 있는 것으로 보

This is an Open Access article distributed under the terms of the Creative Commons Attribution Non-Commercial License (http://creativecommons.org/licenses/by-nc/4.0) which permits unrestricted non-commercial use, distribution, and reproduction in any medium, provided the original work is properly cited.
고되었다. ${ }^{1)}$ 특히 75 세 이상 고령에서의 난청은 인지능력을 30 40\% 더 빠르게 감퇴시킬 수 있으며 난청을 방치할 경우 치매가 생길 확률이 경도난청에서 2 배, 중도난청에서 3 배, 고도 난청에서 5 배가량 높게 나타난다. ${ }^{2,3} 50$ 세 이상인 경우 보청기 등을 통해 난청 치료를 받지 않는 경우 불안감, 망상증, 우울 증 등에 걸릴 확률이 높아지며 18 69세의 난청을 가진 사람 들은 중증 이상의 우울증을 않고 있는 경우가 많다고 한다. ${ }^{3,4}$ 
최근 개발된 인공중이는 기존 보청기와 달리 소리의 진동 을 중이강 내의 이소골로 바로 전달해 줌으로써 고주파수 영 역의 큰 출력을 제공하므로 보다 우수한 말소리 명료도를 기 대할 수 있다. 그러나 이것을 시행하기 위해서는 수술이 필요 하고 내부장치에 포함된 자석으로 인하여 자기공명영상촬영 시 어려움이 있으며 기존의 보청기보다 가격이 비싸다는 단 점이 있다. 비교적 최근에 개발되었고 수술이 필요하다는 점 에서 아직 보청기에 비해 널리 보급되지 않았으며 이에 인공 중이와 인지능력에 관한 연구는 지금까지 이뤄지지 않았다.

본 연구는 동일 난청인에서 보청기를 사용한 경우와 인공 중이를 사용한 경우의 청각학적 이득 및 만족도를 조사하고 각각의 경우의 신경심리검사를 통해 인지능력의 변화를 비 교하고자 한다.

\section{대상 및 방법}

\section{대 상}

2013년 10월부터 2016년 9월까지 중앙보훈병원 이비인후과

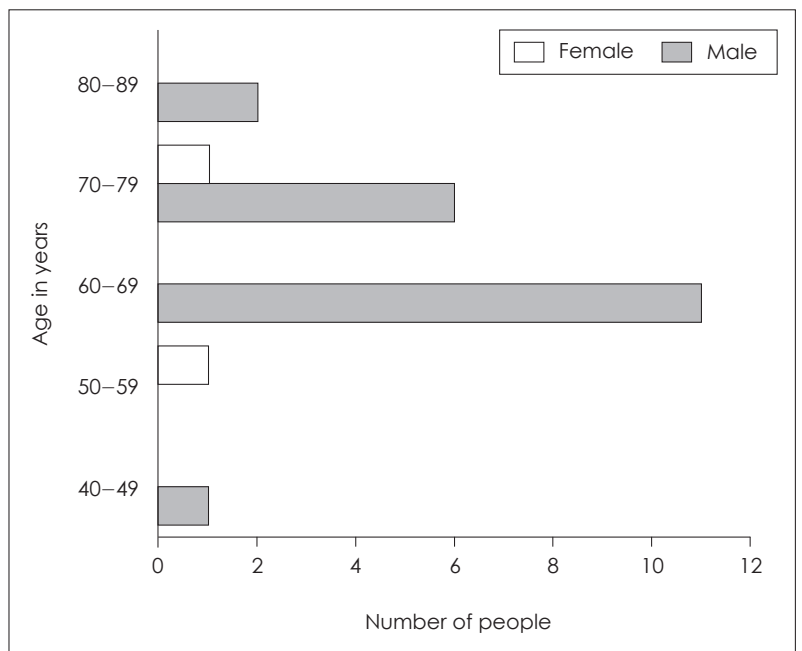

Fig. 1. Gender and age of the experimental group.
를 방문하여 인공중이를 처방받은 환자들 중 22명을 실험군 으로 선정하였다. 모든 대상자들은 인공중이 이식술을 받기 전 최소 3 개월 이상 보청기를 사용한 경력이 있으며 22명의 대 상자 중 남성은 20명, 여성은 2명이고 수술 시 평균연령은 70 세였다(범위: 42 84세, 중앙값: 69세)(Fig. 1). 모든 대상자들 은 이식장치로 Vibrant Sound bridge(Amadé; MEDEL, Innsbruck, Austria)를 사용하였고 우측은 8명, 좌측은 14 명 이었다. 인공중이는 수술 후 약 5 6주 후부터 활성화되었으 며 초기 1 주, 2 주, 1 개월, 3 개월 간격으로 청각사와 피팅 프로 그램인 CONNEXX6 (MEDEL, Innsbruck, Austria)를 진행 하였다.

본 연구에서 학습효과를 확인하기 위해 실험군 외에 대조군 을 선정하였고 동일하게 8주 간격으로 동일한 검사를 2회 시 행하였으며, 대조군은 실험군이 방문한 기간 동안 중앙보훈병 원 신경과에 내원한 환자를 대상으로 무작위 선정하였다 (Table 1).

\section{방 법}

동일 난청인에서 보청기를 사용하지 않았을 경우, 보청기를 사용한 경우, 인공중이를 사용한 경우의 3가지 조건에서 각각 순음청력검사(pure tone audiometry), 어음명료도검사(speech discrimination test)를 시행하였고 인공중이 수술 전과 인공 중이 수술 후 Abbreviated Profile of Hearing Aid Benefit (APHAB) 설문조사를 시행하여 그 평균을 비교하였다. 그 리고 보청기를 사용한 경우와 인공중이를 사용한 경우 신경 심리검사를 실시하였다. 모든 검사결과는 SPSS 18.0(SPSS Inc., Chicago, IL, USA)을 통해 통계학적 분석하였고 $p$ 값 이 0.05 이하인 경우에 의미가 있는 것으로 판정하였다.

\section{순음청력검사, 어음명료도검사}

술 전 헤드폰을 착용한 상태에서 순음청력검사와 어음청력 검사를 실시하였으며 환자 본인의 보청기를 착용한 상태에서

Table 1. Demographic data of control and experimental groups performed before this study

\begin{tabular}{lccc}
\hline & Control group & Experimental group & $p$-value* \\
\hline Number (female) & $20(1)$ & $20(2)$ & 0.649 \\
Age (years) & $68.9 \pm 4.7$ & $70.1 \pm 6.3$ & 0.437 \\
Education & $7.1 \pm 2.2$ & $7.2 \pm 4.7$ & 0.487 \\
K-MMSE & $24.7 \pm 3.2$ & $23.5 \pm 5.8$ & 0.338 \\
CDR & $0.9 \pm 1.9$ & $0.9 \pm 5.1$ & 0.598 \\
SOB & $2.5 \pm 4.7$ & $2.9 \pm 2.1$ & 0.344 \\
Barthel & $20.0 \pm 0.0$ & $20.0 \pm 0.0$ & 0.766 \\
GDS & $5.6 \pm 3.2$ & $4.4 \pm 7.8$ & 0.286 \\
\hline
\end{tabular}

Data are presented as mean \pm standard deviation. *Mann-Whitney $U$ test was used for continuous variable and chi-square test was used for categorical variable. K-MMSE: Korean Mini-Mental State Examination, CDR: Clinical Dementia Rating Scale, SOB: Sum of box, GDS: Geriatric Depression Scale 
기능이득(functional gain)을 측정하였다.

이때 검사는 음장(sound fields)에서 스피커(speaker)를 0 도로 바라본 상태로 검사를 실시하였으며 환자와 스피커의 거 리는 $1 \mathrm{~m}$ 를 유지하였고 자극음은 변조음(frequency modulation)으로 제시하였다. 수술 후 인공중이를 착용했을 때에 도 같은 조건에서 청력검사를 실시하였다. 인공중이 수술 전 1 회, 인공중이 수술 후 1 회 진행하였으며 소요시간은 10 분 내 외였다.

\section{$\mathrm{APHAB}$ 설문조사}

Cox와 Alexander ${ }^{5}$ 가 고안한 $\mathrm{APHAB}$ 설문지는 보청기 착용 전과 보청기 착용 후의 심리사회적 만족도를 평가하는 주관적인 설문항으로 총 4개의 항목(일상적인 의사소통, 반 향음에서 의사소통, 소음환경의 의사소통, 큰 소리에 대한 불쾌감)의 24문항 설문으로 구성되어 있다(Table 2).

설문조사의 결과는 보청기 착용 전과 착용 후의 환자가 느끼
는 장해 정도를 24문항에 대한 설문지에 답하게 하여 4항목 (일상적인 의사소통, 반향음에서 의사소통, 소음환경의 의사소 통, 큰 소리에 대한 불쾌감)에 대해 0점에서 100점까지 보청기 착용 전과 착용 후의 장해 정도를 각각 점수화하고 $(\mathrm{APHAB}$ score), 보청기 착용 전의 장해 정도(prefitting APHAB score) 에서 보청기 착용 후의 장해 정도(postfitting $\mathrm{APHAB}$ score) 를 뺀 값을 만족도 점수로 하여 주관적인 만족도의 지표로 사용한다. $\mathrm{APHAB}$ 점수는 점수가 높을수록 장해가 심한 것 을 의미하며, 만족도 점수(benefit score)는 점수가 높을수록 만족도가 좋아진 것을 의미한다. ${ }^{4}$ 본 연구에서는 $\mathrm{APHAB}$ 를 번안한 설문지를 사용하여 인공중이 수술 환자들의 만족도 를 조사하고자 하였으며 청각사가 인공중이 수술 환자들에게 설문 내용에 대해 알려준 뒤 환자 스스로 체크하도록 하였다. 인공중이 수술 전 보청기 착용 상태에서 1 회, 인공중이 수술 후 1 회 진행하였으며 소요시간은 10 분 내외였다.

Table 2. Twenty-four items of Abbreviated Profile of Hearing Aid Benefit

Ease of communication

1. When I am in a crowded grocery store, talking with the cashier, I can follow the conversation.

2. I miss a lot of information when I'm listening to a lecture.

3. Unexpected sounds, like a smoke detector or alarm bell are uncomfortable.

4. I have difficulty hearing a conversation when I'm with one of my family at home.

5. I have trouble understanding dialogue in a movie or at the theater.

6. When I am listening to the news on the car radio, and family members are talking, I have trouble hearing the news.

Reverberation

1. When I am at the dinner table with several people, and am trying to have a conversation with one person, understanding speech is difficult.

2. Traffic noises are too loud.

3. When I am talking with someone across a large empty room, I understand the words.

4. When I am in a small office, interviewing or answering questions, I have difficulty following the conversation.

5. When I am in a theater watching a movie or play, and the people around me are whispering and rustling paper wrappers, I can still make out the dialogue.

6. When I am having a quiet conversation with a friend, I have difficulty understanding.

Background noise

1. The sounds of running water, such as a toilet or shower, are uncomfortably loud.

2. When a speaker is addressing a small group, and everyone is listening quietly, I have to strain to understand.

3. When I'm in a quiet conversation with my doctor in an examination room, it is hard to follow the conversation.

4. I can understand conversations even when several people are talking.

5. The sounds of construction work are uncomfortably loud.

6. It's hard for me to understand what is being said at lectures or church services.

Aversiveness

1. I can communicate with others when we are in a crowd.

2. The sound of a fire engine siren close by is so loud that I need to cover my ears.

3. I can follow the words of a sermon when listening to a religious service.

4. The sound of screeching tires is uncomfortably loud.

5. I have to ask people to repeat themselves in one-on-one conversation in a quiet room.

6. I have trouble understanding others when an air conditioner or fan is on. 


\section{신경심리검사(Seoul Neuropsychological Screening Battery)}

신경심리검사는 치매 진단에 사용될 수 있을 뿐만 아니라 다양한 신경학적/정신과학적 질환을 않고 있는 환자들의 인 지기능 상태를 종합적으로 평가할 수 있다. 하부 인지 영역별로 살펴보면, 집중력은 Digit Span Test의 forward와 backward, 언어능력은 한국판 보스턴 이름대기 검사(Korean-Boston Naming Test, K-BNT), 시공간능력은 Rey-Osterrieth Complex Figure Test $(\mathrm{RCFT})^{7}$ 의 따라 그리기 점수를 이용하여 알아보았다. 언어적 기억력과 시각적 기억력은 Seoul Verbal Learning Test(SVLT)와 RCFT 각각의 즉각 회상, 지연 회상 및 재인검사 점수를 이용하여 알아보았다. 전두엽 관련 기능

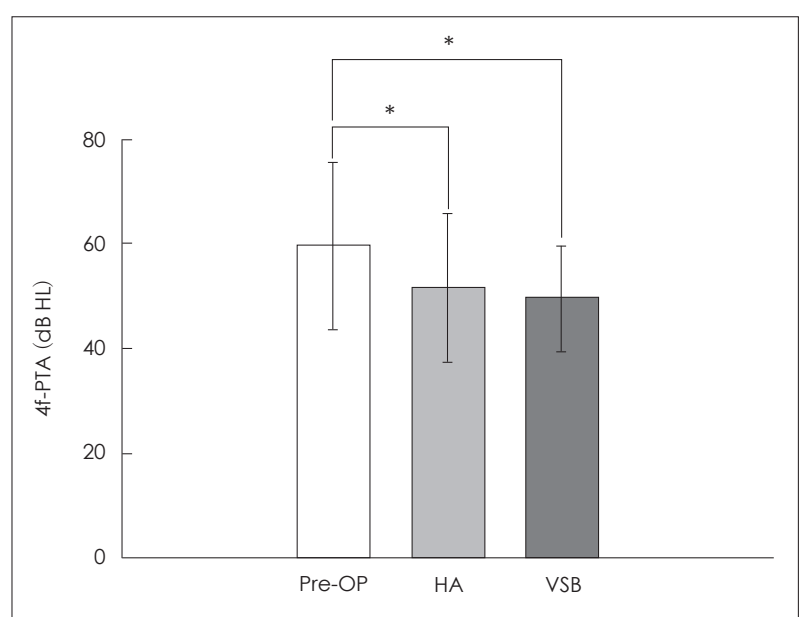

Fig. 2. The 4 frequency-pure-tone hearing average of pre-OP, HA and VSB in the experimental group. The error bars indicating standard deviation. *statistically significant, $p<0.05$. 4f-PTA: 4 frequency-pure-tone hearing average, pre-OP: pre-operation (without HA), HA: hearing aid, VSB: vibration sound bridge.

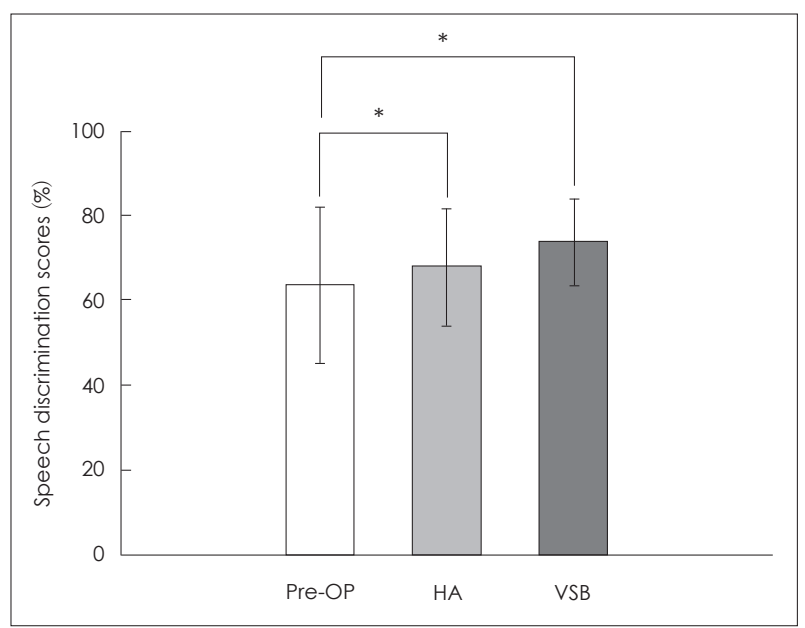

Fig. 3. Speech discrimination scores of pre-OP, HA and VSB in the experimental group. The error bars indicating standard deviation. *statistically significant, $p<0.05$. pre-OP: pre-operation (without HA), HA: hearing aid, VSB: vibration sound bridge.
을 알아보기 위해 통제단어연상검사(Controlled Oral Word Association Test) 및 Go-No-Go 검사를 시행하였다.6.8) 통제 단어연상검는 2가지(동물, 시장) 의미적 단어 유창성(semantic word fluency) 각각의 점수와 3 가지(ᄀ, ㅇ, ㅅ) 음소적 단 어 유창성(phonemic word fluency)의 합산 점수를 이용한 것이다. ${ }^{9)} \mathrm{Go}-\mathrm{No}-\mathrm{Go}$ 검사는 전두엽의 운동 조절기능과 전두 엽 장애를 시사하는 보족증 여부를 평가하는 것으로 검사자 가 손가락을 두 개 올리면 피검자는 한 개를, 검사자가 한 개 를 올리면 피검자는 두 개를 올리도록 하는 contrasting program을 먼저 시행하고 검사자가 두 손가락을 올리면 아무 손 가락도 올리지 않도록 지침을 주었을 때 20회 시행하여 올바 르게 시행한 횟수로 산출하는 것이다. ${ }^{8)}$

신경심리사가 반구조화된 면담을 통해 환자의 기본 신상정 보(나이, 성별, 교육수준 등)를 수집하고 신경심리검사를 실시 하였다. 인공중이 수술 전 1 회, 인공중이 수술 후 1 회 진행하였 으며 검사시간은 1 회기당 약 50 분가량 소요되었고 검사자와 피검자 일대일 개인검사 형식으로 진행하였다.

\section{결 과}

\section{순음청력검사, 어음명료도검사}

순음청력검사에서 4분법상 수술 전 보청기를 착용하지 않 은 경우 $59.60 \mathrm{~dB} \mathrm{HL}$, 보청기 착용 시 $51.62 \mathrm{~dB} \mathrm{HL}$, 인공중이 착용 시 $49.55 \mathrm{~dB}$ HL로 나타났으며 보청기 착용으로 인한 이득은 $7.96 \mathrm{~dB} \mathrm{HL}$, 인공중이 착용으로 인한 이득은 10.00 $\mathrm{dB}$ HL로 나타났다(Fig. 2). 대응표본 T 검정(paired T-test) 을 시행하였을 때 두 경우 모두 통계적으로 유의한 이득이 있 었다(보청기: $p=0.0012$, 인공중이: $p=0.0007$ ).

어음명료도 결과 수술 전 보청기를 착용하지 않은 경우 평균 $63.64 \%$, 보청기 착용 시 평균 $67.73 \%$, 인공중이 착용 시 평균 $73.64 \%$ 로 나타났다. 보청기 착용 시에는 평균 $4.10 \%$ 의 이득 을 보였으며, 인공중이 착용 시에는 평균 $10 \%$ 의 이득을 보이 는 것으로 나타났다(Fig. 3). 정규성 검정을 하였을 때 자료 가 정규분포를 따르지 않아 대응표본 $\mathrm{T}$ 검정(paired T-test) 대신에 비모수적 방법인 윌콕슨 부호-순위 검정(Wilcoxon signed-rank test)을 시행하였고, 통계분석 결과 보청기를 착 용한 경우와 인공중이를 착용한 경우 모두 통계적으로 유의 한 이득이 있었다(보청기: $p=0.0234$, 인공중이: $p=0.0042$ ).

\section{$\mathrm{APHAB}$ 결과}

본 연구 대상자 22명에게 APHAB 설문조사를 실시하였으 나 불충분한 답변을 한 3 명은 제외하고 모든 설문항에 적절 히 답변을 한 19 명의 $\mathrm{APHAB}$ 결과를 분석하였다. 인공중이 수 
술 전의 APHAB score는 보청기를 착용한 상태의 결과이다. 일 상적인 의사소통 항목에서 인공중이 수술 전의 평균 $\mathrm{APHAB}$ score가 23.53점, 인공중이 수술 후의 평균 $\mathrm{APHAB}$ score가 17.63점, 만족도 점수(benefit score)는 5.89점이었고 반향음에 서 의사소통 항목의 경우 인공중이 수술 전의 평균 $\mathrm{APHAB}$

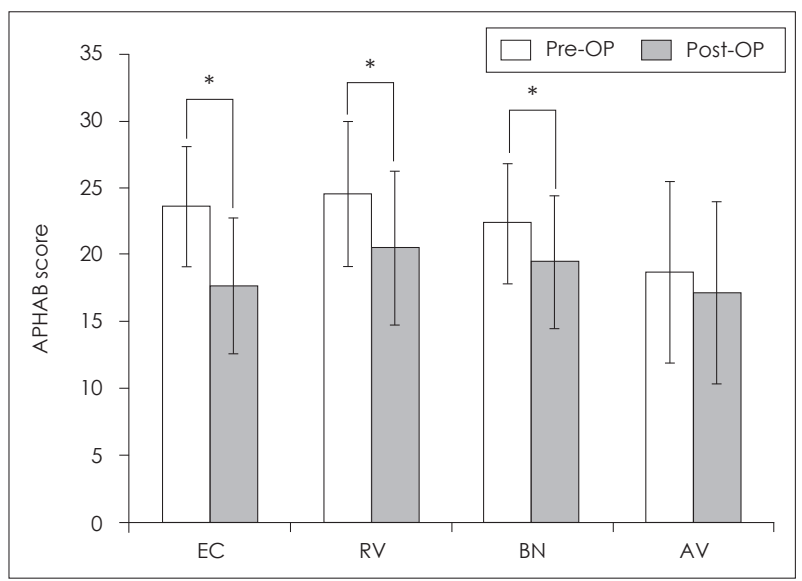

Fig. 4. APHAB score of pre-OP and post-OP in the experimental group. *statistically significant, $p<0.05$. The error bars indicating standard deviation. pre-OP: pre-operation (with HA), post-OP: postoperation (with VSB), HA: hearing aid, VSB: vibration sound bridge, APHAB: abbreviated profile of hearing aid benefit, EC: ease of communication, RV: reverberation, BN: background noise, AV: aversiveness. score가 24.53점, 인공중이 수술 후의 평균 $\mathrm{APHAB}$ score는 20.53점, 만족도 점수(benefit score)는 4.00점이었다. 소음환 경의 의사소통 항목에서는 인공중이 수술 전의 평균 $\mathrm{APHAB}$ score가 22.32점, 인공중이 수술 후의 평균 APHAB score는 19.42점, 만족도 점수(benefit score)는 2.89점이었으며 큰 소리 에 대한 불쾌감 항목의 경우 인공중이 수술 전의 평균 $\mathrm{APHAB}$ score는 18.63점, 인공중이 수술 후의 평균 APHAB score가 17.16점, 만족도 점수(benefit score)는 1.47점이었다.

대응표본 T 검정(paired T-test)을 시행하였을 때, 일상적인 의사소통 항목, 반향음에서의 의사소통 항목, 소음환경의 의 사소통 항목은 인공중이 수술 후 만족도가 통계적으로 유의미 하게 증가한 것으로 나타났다(ease of communication: $p$ $<0.0001$, reverberation: $p=0.0002$, background noise: $p=0.0061)$. 하지만 큰 소리에 대한 불쾌감 항목의 경우 인공 중이 수술 후 만족도가 증가하였으나, 통계적으로 유의미한 차이는 아니었다(aversiveness: $p=0.2165$ )(Fig. 4).

\section{신경심리검사 결과}

본 연구 대상자 22명 모두 신경심리검사를 실시하였으나 불충분한 답변을 한 2명을 제외하였다. Korean Mini-Mental State Examination 점수에서는 인공중이를 착용한 경우 보

Table 3. Comparison of neuropsychological tests between control group and experimental group, at 0 week and 8 weeks

\begin{tabular}{|c|c|c|c|c|c|}
\hline \multirow{2}{*}{ Neuropsychological tests } & \multicolumn{2}{|c|}{ Control group } & \multicolumn{2}{|c|}{ Experimental group } & \multirow{2}{*}{$p$-valuet } \\
\hline & Week 0 & Week 8 & Week $0(\mathrm{HA})$ & Week 8 (VSB) & \\
\hline Digit forward & $3.70 \pm 0.95$ & $3.50 \pm 0.97$ & $3.40 \pm 0.52$ & $4.40 \pm 1.07$ & $0.044^{*}$ \\
\hline Digit backward & $4.80 \pm 1.32$ & $5.20 \pm 0.92$ & $3.60 \pm 0.84$ & $5.00 \pm 1.33$ & $0.048^{*}$ \\
\hline K-BNT & $47.63 \pm 8.24$ & $48.38 \pm 8.70$ & $35.20 \pm 7.84$ & $48.00 \pm 6.57$ & $0.037^{*}$ \\
\hline SVLT immediate recall & $13.79 \pm 6.18$ & $16.60 \pm 5.38$ & $12.20 \pm 3.79$ & $16.30 \pm 6.04$ & 0.511 \\
\hline SVLT delayed recall & $2.89 \pm 2.33$ & $3.50 \pm 2.92$ & $2.20 \pm 2.25$ & $4.39 \pm 3.10$ & 0.154 \\
\hline RCFT copy & $32.15 \pm 6.37$ & $32.55 \pm 6.58$ & $24.40 \pm 7.78$ & $29.65 \pm 10.30$ & 0.132 \\
\hline RCFT immediate copy & $10.70 \pm 8.50$ & $12.00 \pm 9.61$ & $7.70 \pm 7.11$ & $11.40 \pm 8.56$ & 0.423 \\
\hline RCFT delayed copy & $10.45 \pm 8.37$ & $12.35 \pm 10.33$ & $7.40 \pm 7.21$ & $11.05 \pm 8.50$ & 0.549 \\
\hline Contrasting & $20.00 \pm 0.00$ & $20.00 \pm 0.00$ & $20.00 \pm 0.00$ & $19.80 \pm 0.63$ & 0.331 \\
\hline Go-no-go & $14.30 \pm 5.38$ & $13.50 \pm 5.44$ & $11.80 \pm 4.92$ & $16.69 \pm 4.47$ & $0.008^{*}$ \\
\hline Fist-edge-arm & $1.25 \pm 0.46$ & $1.25 \pm 0.46$ & $1.67 \pm 0.52$ & $1.50 \pm 0.55$ & 0.678 \\
\hline COWAT animal & $12.80 \pm 3.94$ & $11.80 \pm 4.32$ & $10.40 \pm 2.72$ & $11.90 \pm 3.28$ & 0.147 \\
\hline COWAT supermarket & $12.81 \pm 7.21$ & $13.40 \pm 5.04$ & $10.40 \pm 4.09$ & $12.20 \pm 3.30$ & 0.515 \\
\hline COWAT phonemic & $21.60 \pm 11.58$ & $23.59 \pm 12.23$ & $16.00 \pm 4.16$ & $21.69 \pm 8.20$ & 0.142 \\
\hline K-MMSE & $25.7 \pm 3.06$ & $25.10 \pm 3.11$ & $23.8 \pm 3.86$ & $25.90 \pm 3.67$ & $0.066^{*}$ \\
\hline CDR & $0.70 \pm 0.26$ & $0.70 \pm 0.26$ & $0.80 \pm 0.26$ & $0.55 \pm 0.28$ & $0.038^{*}$ \\
\hline $\mathrm{SOB}$ & $2.40 \pm 2.47$ & $2.30 \pm 2.36$ & $4.00 \pm 2.21$ & $2.25 \pm 2.14$ & $0.045^{*}$ \\
\hline GDS & $5.70 \pm 2.63$ & $5.70 \pm 5.19$ & $7.80 \pm 7.00$ & $6.50 \pm 6.35$ & 0.264 \\
\hline
\end{tabular}

Data are presented as mean \pm standard deviation. *statistical significance between HA and VSB in the experimental group ( $p$ $<0.05$ ), trepeated measures of General Linear Model was used. K-BNT: Korean version of the Boston Naming Test, SVLT: Seoul Verbal Learning Test, RCFT: Rey-Osterrieth Complex Figure Test, COWAT: Controlled Oral Word Association Test, K-MMSE: Korean Mini-Mental State Examination, CDR: Clinical Dementia Rating Scale, SOB: Sum of box, GDS: Geriatric Depression Scale, HA: hearing aid, VSB: vibration sound bridge 
청기 착용 시 $23.8 \pm 3.86$ 에 비해 $25.90 \pm 3.67$ 로 유의하게 향상 을 보였고 Clinical Dementia Rating Scale 점수에서는 인공 중이를 착용한 경우 보청기 착용 시 $0.80 \pm 0.26$ 에 비해 0.55 \pm 0.28 로 유의하게 감소하는 경향을 보였다. 신경심리검사에 서 digit forward span은 보청기 사용 시보다 인공중이 사용 시 $3.40 \pm 0.52$ 에서 $4.40 \pm 1.07$ 로 대조군에 비해 향상되었고, digit backward span은 보청기 사용 시보다 인공중이 사용 시 $3.60 \pm 0.84$ 에서 $5.00 \pm 1.33$ 으로 대조군에 비해 뚜렷한 향 상을 보였다. K-BNT는 보청기 사용 시보다 인공중이 사용 시 $35.20 \pm 7.84$ 에서 $48.00 \pm 6.57$ 로 대조군에 비해 뚜렷한 향상을 보였다. 기억력은 대조군과 차이를 보이진 않았다(Table 3). 통 제단어연상검사의 경우 대조군에 비해 향상된 결과를 보였으 나 유의한 결과는 아니었고 Go-No-Go 검사의 경우 $11.80 \pm$ 4.92에서 $16.69 \pm 4.47$ 로 유의하게 향상된 결과를 보였다. 종 합적으로 볼 때 인공중이 군에서 언어능력, 주의 집중력, 전두 엽 관련 기능 검사에서 대조군에 비해 향상된 결과를 나타냈 다(Table 3).

\section{고 찰}

인지기능은 일반적으로 자신과 주위환경에 대한 정보의 입 수, 처리, 저장 및 검색과 관련한 광범위한 지적능력을 말한 다. ${ }^{10)}$ 의사소통 과정은 신호를 받아들이는 청각 기관, 신호를 받아들이는 청각중추, 인지기능을 담당하는 전두엽 피질이 나 편도체 등과 유기적인 정보 교환으로 이루어진다. ${ }^{11}$ 청각 검사를 통해 인지능력을 측정하는 방법으로 소음환경에서 시행한 어음명료도가 인지기능을 반영할 수 있다. ${ }^{12)}$

청력과 인지능력에 대한 학문적인 연구는 1980년대부터 이뤄져 왔고 논란은 있으나 난청이 인지능력 및 지적 능력에 영향을 준다는 결과가 보고되었다. ${ }^{13)}$ 난청이 인지능력 저하와 상관성을 이루는 기전에 대한 가설은 대략 3가지로 요약할 수 있다. 첫째는 공통원인 가설(common cause theory)로 난청 과 인지능력 저하는 노화된 두뇌의 신경퇴행에 따른 결과로 보는 것이고 둘째는 캐스케이드 가설(cascade theory)로 청각 자극의 감소가 직접적으로 인지능력 저하에 영향을 끼치거나 간접적으로 난청으로 인한 사회활동의 감소가 인지능력 저 하를 야기한다는 것이다. ${ }^{9)}$ 셋째는 인지부하 가설(cognitive load theory)은 난청인 경우 인지기능을 유지하기 위해 정신 적 노력이 더 요구되고 인지적 능력이 전환되거나 독점됨으 로써 쇠퇴를 초래한다는 것이다.") 난청이 인지능력 저하를 가 져올 수 있다는 보고들은 보청기나 인공와우에 의해 난청이 개선되는 경우 인지능력 향상을 가져올 수 있다는 가설을 가 능하게 하였고 이에 대한 연구들은 대부분 이 가설에 부합
하는 결과가 보고되었다.914,15) 적절한 청각자극과 증폭된 소 리자극이 청각 뇌의 가소성을 유도한다는 가설이 쥐를 이용 한 음향심리검사를 통해 증명되었고, 이는 증폭된 소리자극 이 청각 가소성에 영향을 미쳐 사람의 뇌에서도 청각 재활이 이루어지도록 한다는 것을 유추할 수 있게 하였다. ${ }^{14,16)}$ 이런 특성은 일측 보청기만을 착용하는 경우 반대편 말소리 인지 능력이 저하되는 현상(late onset deprivation effect)이 나타 나고 다시 반대편에도 보청기를 사용하게 되면 부분적으로 회복되는 현상에 대한 설명을 가능하게 한다. ${ }^{15}$

인공중이 수술은 1990년대 처음 개발되어 1996년 처음으로 시술되었고 현재까지 1000 명 이상의 환자가 시술되었으며 국 내에서는 2011년부터 시술되기 시작하였다. ${ }^{17)}$ 인공중이는 보 청기와 인공와우에 비해 비교적 최근에 소개되어 인지능력과 의 상관관계에 대한 보고는 아직 이뤄지지 않았다.

이번 연구에서 인공중이 수술 후의 인지능력의 변화는 대부 분의 인지능력검사에서 보청기나 인공와우의 경우처럼 향상 됨을 확인할 수 있었다. 인지능력검사 중 $p$ 값이 0.05 이하인 통계적 유의성을 보인 7가지 검사에서 보청기를 착용하는 경 우보다 인공중이를 착용하는 경우에서 더 좋은 결과를 나타 냈다.

통제단어연상검사에서는 유의한 차이를 보이지 않았는데 우선 대상군의 부족이 통계적 유의성을 만들어내지 못하였을 가능성이 있고, 장기 기억과 연관성이 없는 $\mathrm{Go}-\mathrm{No}-\mathrm{Go}$ 검사 의 경우 유의한 향상을 보이는 것과는 달리 생성 이름 대기, 기억의 재인, 범주화 등의 검사과정은 장기 기억에서 능동적 으로 낱말을 찾아내는 과정이 필요하므로 단기간의 청력 및 인지능력 향상이 결과에 영향을 주기는 어려웠을 것으로 보 인다. ${ }^{18)}$

본 연구의 한계점으로 대상자 수가 적다는 점, 추적관찰 기간이 짧았다는 점, 신경심리검사의 학습 효과가 있을 수 있다는 점 등을 들 수 있다. 19세기 이전부터 있었던 보청기 나 1970년대부터 인공와우 수술이 시작되었던 것에 비해 인 공중이 수술은 역사가 짧기 때문에 연구 대상자가 상대적으 로 적고 추적 기간도 짧을 수밖에 없다. 신경심리검사는 재실 시 기간이 8주로 상대적으로 짧았으며 환자의 신경심리검사 에서 발생할 수 있는 학습 효과(learning effect)를 완전히 배제할 수 없었다. 하지만 대조군의 대부분 검사에서 8 주 간 격으로 시행된 2회의 결과가 거의 유사하게 나왔으며 상승하 거나 하락한 항목들의 경우에도 대조군의 경우는 실험군에 비해 현저한 차이는 관찰되지 않아 학습 효과는 미미한 것으 로 보인다. 그러므로 통계적 유의성을 확보한 신경심리검사 들을 토대로 보건대, 인공중이의 청력재활 효과가 보청기에 비해 상대적으로 우수하고 이에 따라 인지능력의 향상을 가 
져온 것으로 볼 수 있다.

난청이 발생하게 되면, 타인과의 대화가 힘들어지면서 의 사소통과 관련된 행동장애와 사회심리적 장애를 겪게 되고 이에 따라 자신감이 떨어지면서 사회적 행동이 위축되고, 이 차적으로 인지능력의 저하를 겪게 되어 삶의 질이 저하될 수 있다. ${ }^{19)}$ 따라서, 노인 인구의 증가에 따른 난청 환자의 증가가 예상되므로 삶의 질 향상을 위해 난청의 조기 진단과 청력재 활은 중요성을 더해가고 있다. 본 연구의 대상자 수가 아직 많지 않았으나 앞으로 늘어날 사용 환자의 추세에 비추어 더 많은 환자군을 포함하여 지속적인 추적연구 및 대응이 필요 할 것이다.

\section{Acknowledgments}

This study was supported by a VHS Medical Center Research Grant, Republic of Korea (grant number: VHSMC16015).

\section{REFERENCES}

1) World Health Organization. Deafness and hearing loss 2017 [cited 2017 Apr 2] Available from: http://www.who.int/mediacentre/factsheets/ fs300/en/.

2) Lin FR, Yaffe K, Xia J, Xue QL, Harris TB, Purchase-Helzner E, et al. Hearing loss and cognitive decline in older adults. JAMA Internal Medicine 2013;173(4):293-9.

3) Lin FR, Metter EJ, O'Brien RJ, Resnick SM, Zonderman AB, Ferrucci L. Hearing loss and incident dementia. Arch Neurol 2011;68(2):214-20.

4) James BD, Wilson RS, Barnes LL, Bennett DA. Late-life social activity and cognitive decline in old age. J Int Neuropsychol Soc 2011; 17(6):998-1005.

5) Cox RM, Alexander GC. The abbreviated profile of hearing aid benefit. Ear Hear 1995;16(2):176-86.

6) Kang Y, Kim H, Na DL. Parallel short forms for the Korean-Boston
Naming Test (K-BNT). J Korean Neurol Assoc 2000;18(2):144-50.

7) Shin MS, Park SY, Park SR, Seol SH, Kwon JS. Clinical and empirical applications of the Rey-Osterrieth Complex Figure Test. Nat Protoc 2006;1(2):892-9.

8) Jeong Y, Na DL. Bedside evaluation of neurobehavioral disorders. J Korean Neurol Assoc 2002;20(4):325-38.

9) Cosetti MK, Pinkston JB, Flores JM, Friedmann DR, Jones CB, Roland JT Jr, et al. Neurocognitive testing and cochlear implantation: insights into performance in older adults. Clin Interv Aging 2016;11: 603-13.

10) McAllister TW. Cognitive functioning in the affective disorders. Compr Psychiatry 1981;22(6):572-86.

11) Song SJ, Shim HJ, Park CH, Lee SH, Yoon SW. Analysis of correlation between cognitive function and speech recognition in noise. Korean J Otorhinolaryngol-Head Neck Surg 2010;53(4):215-20.

12) Zekveld AA, Deijen JB, Goverts ST, Kramer SE. The relationship between nonverbal cognitive functions and hearing loss. J Speech Lang Hear Res 2007;50(1):74-82.

13) Uhlmann RF, Larson EB, Rees TS, Koepsell TD, Duckert LG. Relationship of hearing impairment to dementia and cognitive dysfunction in older adults. JAMA 1989;261(13):1916-9.

14) Noh H. Rehabilitation for the elderly or presbycusis using hearing aids. Korean J Otorhinolaryngol-Head Neck Surg 2007;50(10):84653.

15) Gelfand SA. Long-term recovery and no recovery from the auditory deprivation effect with binaural amplification: six cases. J Am Acad Audiol 1995;6(2):141-9.

16) Willott JF. Physiological plasticity in the auditory system and its possible relevance to hearing aid use, deprivation effects, and acclimatization. Ear Hear 1996;17(3 Suppl):66S-77S.

17) Hwang KR, Choi JY. Middle ear implant. Hanyang Med Rev 2015; 35(2):103-7.

18) Lee KS, Park CI, Kim HH, Park ES. Development of generative naming ability in 3, 4, 5 and 6-year-old children. Commun Sci Disord 2004; 9(3):1-21.

19) Choi J, Chung WH. Age-related hearing loss and the effects of hearing aids. J Korean Med Assoc 2011;54(9):918-24. 